\title{
SISTEM INFORMASI PENJUALAN MOTOR SECARATUNAI PADA YAMAHA VICTORY DEPOK BERBASIS JAVA
}

\author{
Septian Tri Argi ${ }^{1}$, Aan Risdiana ${ }^{2}$ \\ Program Studi Informatika, Fakultas Teknik dan Ilmu Komputer, Universitas Indraprasta PGRI \\ Jalan Raya Tengah No 80, Kelurahan Gedong, Pasar Rebo, Jakarta Timur \\ septiantriargi@gmail.com ${ }^{1}$, risdi_ann@live.com²
}

\begin{abstract}
Abstrak
Penelitian ini bertujuan untuk membuat aplikasi penjualan di Yamaha Victory Depok, serta mendeskripsikan hasil uji coba sistem aplikasi penjualan. Metode penelitian yang digunakan dalam perancangan aplikasi ini adalah metode Grounded Research. Yaitu suatu metode penelitian yang mendasarkan diri kepada fakta dan menggunakan analisa perbandingan bertujuan untuk mengadakan generalisasi empiris, menetapkan konsepkonsep, membuktikan teori dan mengembangkan teori dimana pengumpulan data dan analisa data berjalan pada waktu yang bersamaan. Pada metode ini data menjadi dasar pembentukan teori. Peneliti mengumpulkan data langsung di Yamaha Victory. Dengan metode wawancara langsung kepada pemilik perusahaan dan karyawannya. Tidak hanya wawancara, peneliti juga melakukan observasi di Yamaha Victory. Data yang diperoleh dianalisa sebagai pembentukan teori yang menjadi dasar pembuatan aplikasi penjualan. Selama penelitian, peneliti menemukan berbagai masalah yang dihadapi di perusahaan tersebut yaitu kendala sistem yang masih sangat manual sehingga pekerjaan tidak cepat dan efektif. Dapat disimpulkan bahwa dengan adanya aplikasi yang sudah terkomputerisasi, transaksi di penjualan semakin mudah dan cepat.
\end{abstract}

Kata Kunci: Sistem Informasi, Aplikasi Penjualan, Java

\begin{abstract}
The research aims to create sales applications at Yamaha Victory Depok, as well as describe the results of trial system sales applications. The method of research used in designing this application is the method of Grounded Research. A research method that bases itself on the facts and uses comparative analysis aims to conduct empirical generalizations, define concepts, prove theories and develop theories where data collection and analysis Data runs at the same time. In this method the data becomes the basis of theoretical formation. Researchers collect data directly at Yamaha Victory. With a direct interview method to the owner of the company and its employees. Not only interviews, researchers also take observations at Yamaha Victory. The Data obtained is analyzed as the foundation of theoretical development of sales application. During the study, researchers found a variety of problems encountered in the company is the constraints of systems that are still very manual so that the work is not fast and effective. It can be concluded that with a computerized application, transactions in sales are easier and faster.
\end{abstract}

Keywords: Information Systems, Sales Applications, Java

\section{PENDAHULUAN}

Dalam era modern sekarang ini, perkembangan dalam bidang teknologi saat ini hampir menggantikan sistem manual dengan sistem komputerisasi. Perkembangan teknologi tersebut misalnya teknologi komputer baik hardware maupun software yang sebagian besar berperan dalam kehidupan manusia saat ini. Semakin pesatnya perkembangan teknologi dan sistem tersebut. Sistem adalah sekelompok elemen-elemen yang terintegrasi dengan tujuan yang sama untuk mencapai tujuan. Sistem juga merupakan suatu jaringan kerja dari prosedur yang berhubungan, terkumpul bersama-sama untuk melakukan suatu kegiatan atau tujuan tertentu (Yakub, 2014). Dibidang perdagangan saat ini juga banyak yang menggunakan teknologi komputer, kini mini market dan juga pasar swalayan banyak menggunakan teknologi informasi komputer, dengan tujuan untuk mempermudah proses administrasi pengelolahan dalam toko dan memudahkan memperoleh informasi penjualan pada toko tersebut serta meminimalisasikan kesalahan penghitungan dalam transaksi proses jual beli. Informasi disini dapat diartikan yaitu data yang telah diorganisasi dan telah memiliki kegunaan dan manfaat (Krismaji, 2015). 
Dealer Yamaha Victory Depok adalah dealer resmi Yamaha yang melayani penjualan kendaraan motor secara tunai. Dealer Yamaha Victory Depok mempunyai omzet yang lumayan besar. Namun, perusahan ini hingga saat ini belum memiliki teknologi yang sekiranya diperlukan untuk membantu mengontrol data-data harian terutama data penjualan. Data penjualan barang masih dikelola menggunakan pembukuan dan Microsoft Excel, akibatnya file data penjualan barang sulit dicari. Pimpinan perusahaan juga tidak bisa mengetahui jumlah barang yang akan disediakan dalam periode berikutnya.

Penelitian yang dilakukan di Yamaha Victory Depok bertujuan untuk mengumpulkan data-data yang dibutuhkan untuk keperluan analisis sistem informasi penjualan. Data-data ini akan membantu tujuan-tujuan penelitian selanjutnya. Diantaranya, untuk membuat aplikasi sistem informasi penjualan secara tunai di Yamaha Victory menggunakan bahasa pemrograman Java dan juga untuk memberikan solusi yang efektif dan efisien melalui perancangan sistem informasi penjualan motor di Yamaha Victory terutama dalam proses administrasi dan penyimpanan data. Java adalah bahasa pemograman yang dapat dijalankan di berbagai jenis komputer dan berbagai jenis sistem operasi termasuk telepon genggam. Java dikembangkan oleh Sun Microsystem dan dirilis tahun 1995. Java merupakan suatu teknoogi perangkat lunak yang digolongkan multi platform. Selain itu, Java juga merupakan satu platform yang memiliki virtual machine dan library yang diperlukan untuk menulis dan menjalankan suatu program (Wahana, 2015). Aplikasi ini juga menggunakan database MySQL. MySQL merupakan sebuah program database server yang mampu menerima dan mengirimkan datanya dengan sangat cepat, multi user serta menggunakan perintah standar SQL (Stuctured Query Language) (Nugroho, 2014). Dan juga menggunakan perangkat pendukung lainnya seperti Xampp. XAMPP adalah perangkat lunak (free Software) bebas, yang banyak mendukung sistem informasi, yang merupapakan kompilasi dari beberapa program (MADCOMS, 2016).

Sedangkan manfaat yang diharapkan akan diperoleh dari penelitian ini adalah dengan penggunaan sistem informasi penjualan akan sangat membantu perusahaan dalam sistem pengolahan data penjualan dan transaksi penjualan. Karena berdasarkan data penjualan barang pada periode lalu perusahaan dapat mengetahui jumlah penjualan diperiode yang akan datang serta dengan dibangunnya sistem penjualan ini, perusahaan dapat memprediksi jumlah persediaan atau stok aman yang harus disediakan pada periode penjualan berikutnya secara terperinci.

\section{PENELITIAN RELEVAN}

Penelitian relevan merupakan penelitian terdahulu atau sebelumnya yang relevan dengan konsep penelitian sehingga menjadi acuan atau dasar mengembangkan suatu hasil penelitian sebelumnya. Berikut peneliti mengambil sumber dari beberapa penelitian dari jurnal yang berjudul "Perancangan Aplikasi Penjualan Barang Berbasis Dekstop pada CV. Metro Rantau Prapat" disusun oleh Defri Ananta tahun 2013. Dengan hasil data yang dikumpulkan dapat disimpulkan sistem konvensional dengan pendataan manual pada setiap transaksi yang dilakukan. Cara konvensional ini tidak efisien dan memungkinkan kesalahan dan kehilangan data lebih riskan terjadi (Ananta, 2013). Yang kedua penelitian yang berjudul "Perancangan Sistem Informasi Penjualan Barang Handmade Berbasis Website Dengan Metode Waterfall" disusun oleh Rahmat Hidayat, Siti Marlina, Lila Dini Utami tahun 2017. Dengan hasil data, melalukan penelitian terhadap sistem penjualan online mencakup data kasir dan data barang, yang bertujuan agar sistem penjualan barang handmade lebih efektif serta memeksimalkan proses pencarian barang, data kasir (Hidayat, Marlina, \& Utami, 2017).

\section{METODE PENELITIAN}

Metode penelitian yang digunakan peneliti adalah metode grounded (Grounded Reaserch) yaitu suatu metode penelitian berdasarkan pada fakta dan menggunakan analisa perbandingan dengan tujuan mengadakan generalisasi empiris, menetapkan konsep, membuktikan teori, mengembangkan teori, pengumpulan dan analisa data dalam waktu yang bersamaan. Dalam penelitian ini data merupakan sumber teori atau teori berdasarkan data. Mengolah dan menganalisa data membangun hipotesis menjadi teori serta menulis draft laporannya dari waktu ke waktu. 
Setelah melakukan pengumpulan data peneliti melanjutkan proses penelitian sesuai dengan langkah-langkah pokok yang digunakan pada metode ini, yaitu menentukan masalah yang ingin diselidiki, mengumpulkan masalah yang ditemukan serta membuat laporan hasil penelitian.

\section{a. Survei}

Survei ini dilakukan untuk mengamati secara langsung proses yang digunakan oleh Dealer Yamaha Victory.

\section{b. Studi Pustaka}

Studi pustaka dilakukan untuk memperoleh data sekunder dan dasar teori ataupun konsep yang berhubungan dengan penelitian, yaitu dengan membaca dan menelaah literatur-literatur yang berkaitan dengan pembahasan dalam penelitian seperti buku-buku, artikel di internet maupun dokumen. Dari referensi-referensi tersebut, diambil teori-teori yang dapat dijadikan landasan untuk menganalisa permasalahan yang ditemukan selama penelitian.

\section{c. Studi Lapangan}

Studi lapangan merupakan metode untuk memperoleh data yang ada pada saat penelitian. Metode studi lapangan ini peneliti lakukan untuk melihat langsung terhadap penerapan sistem penjualan yang ada pada Yamaha Victory Depok. Dalam studi lapangan ini digunakan teknik wawancara. Teknik pengumpulan data ini dilakukan dengan cara bertanya langsung (wawancara). peneliti melakukan wawancara dengan karyawan Dealer Yamaha Victory bagian administrsi yang bernama Bapak Suherman dan Ibu Nani mengenai bagaimana Sistem penjualan tunai yang berlangsung, dan bagaimana prosedur penjualan tunai di Dealer Yamaha Victory, dengan tujuan agar dapat mengerti perancangan yang selama ini sudah dipakai. Diharapakan dari metode ini dapat diketahui kendala-kendala yang dialami pada tempat tersebut.

\section{d. Analisis Perancangan}

1. Analisa Kebutuhan Sistem, Dalam tahapan perancangan sistem informasi sangat perlu menggunakan analisa kebutuhan, dapat berguna untuk memperoleh data-data yang akan digunakan sebagai inputan sistem informasi dari pengolahan data penjualan.

2. Perancangan sistem informasi merupakan pengembangan sistem baru dari sistem lama yang telah ada, dimana masalah-masalah yang ada pada sistem yang lama diharapkan dapat teratasi pada sistem yang baru dan dapat diimplementasikan dengan kebutuhan pengguna.

3. Desain Aplikasi, pada tahap ini akan dilakukan perancangan struktur data, karakteristik antarmuka, dan tampilan layar dari sistem yang akan dirancang agar menarik dan juga menghibur.

4. Pengkodean dan pengujian system, Sebelum sistem dijalankan maka harus melaksanakan pembuatan "SISTEM PENJUALAN MOTOR SECARA TUNAI PADA YAMAHA VICTORY DEPOK BERBASIS JAVA" dengan perintah kode program. Setelah proses pengkodean selesai maka akan dilakukan proses pengujian terhadap program yang dirancang untuk mengetahui apakah program sudah berjalan dengan benar dan baik sesuai dengan desain yang dilakukan sebelumnya.

5. Implementasi dan evaluasi, implementasi dilakukan untuk memsatikan apakah semua sistem berjalan dengan baik, dan apakah ada kesalahan pada sistem. Implementasi atau pengujian amat sangat penting dilakukan untuk menjadi peninjau akhir terhadap spesifikasi, desain serta pengkodean. Proses evaluasi dilakukan melalui testing aplikasi untuk mengecek jika terdapat error yang bisa menghentikan program secara tiba-tiba ataupun terdapat fungsi-fungsi yang tidak berjalan sesuia dengan apa yang telah ditentukan.

6. Tahap Penelitian laporan. tahap ini dilakukan pengolahan, analisa, dan pembahasan hasil penelitian serta kesimpulan dari hasil penelitian yang telah dilakukan selama masa penelitian.

\section{HASIL DAN PEMBAHASAN}

Pada proses sistem data inventory Yamaha Victory Depok yang sedang berjalan pada penyimpaan data atau persiapan data sudah menggunakan fasilitas komputer akan tetapi masih menggunakan 
aplikasi Ms. Excel. Sehingga memumungkan penyimpanan data membutuhkan banyak tabel. Aturan bisnis sistem yang sedang berjalan pada Yamaha Victory Depok sebagai berikut:

1. Proses Persediaan

a. Pihak gudang melakukan pengecekan rutin terhadap barang.

b. Setelah melakukan pengecekan, lalu memberikan data kepada admin stok unit.

2. Proses Pemesanan Barang

a. Barang yang dibeli sesuai dengan pesanan .

b. Yamaha Victory Depok memberikan daftar barang yang di pesan kepada supplier.

c. Pemilik perusahaan melunasi transaksi pembelian.

3. Proses Penjualan Barang

a. Konsumen mengisi data diri.

b. Admin Menawarkan Motor yang akan dibeli konsumen.

c. Konsumen melakukan pembayaran.

Analisis permasalahan dari penelitian ini adalah, proses penjualan motor secara tunai pemeriksaan keuangan masih dilakukan secara manual dengan menggunakan media kertas. Sistem penjualan motor secara tunai yang belum terkomputerisasi menyebabkan lambannya pekerjaan para karyawan dalam melayani penjualan motor. Kurangnya sumber daya manusia yang memahami sistem komputerisasi menjadi suatu penyebab belum dibuatnya sistem administrasi pemeriksaan penjualan motor secara tunai yang terkomputerisasi.

Maka alternatif penyelesaian masalah yang dapat di simpulkan adalah perancangan sistem penjualan motor secara tunai yang terkomputerisasi sehingga pekerjaan menjadi lebih cepat, tepat dan akurat. Perancangan database untuk sistem penjualan sehingga penyimpanan data tidak menggunakan media kertas melainkan berupa hard disk atau media penyimpanan elektronik lainnya membuat sistem penjualan mudah dipahami oleh karyawan/kasir.

Berikut ini adalah Gambaran sistem yang diusulkan pada penjualan di Yamaha Victory Depok secara keseluruhan dalam diagram konteks.

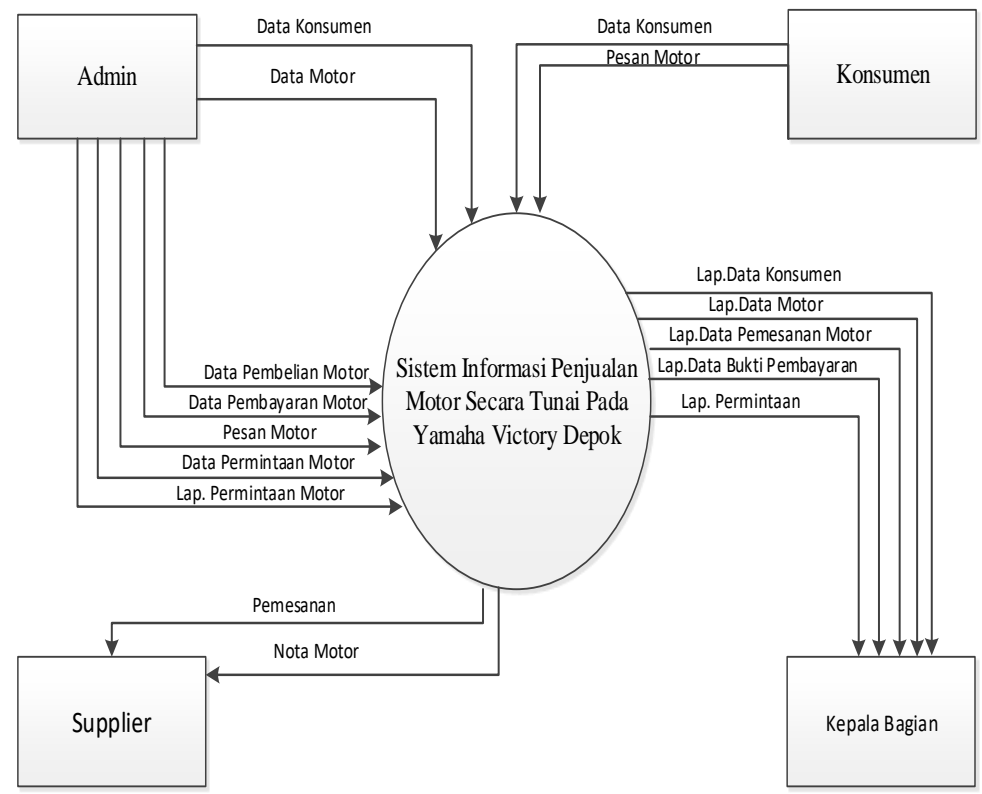

Gambar 1. Diagram Konteks Sistem Penjualan 


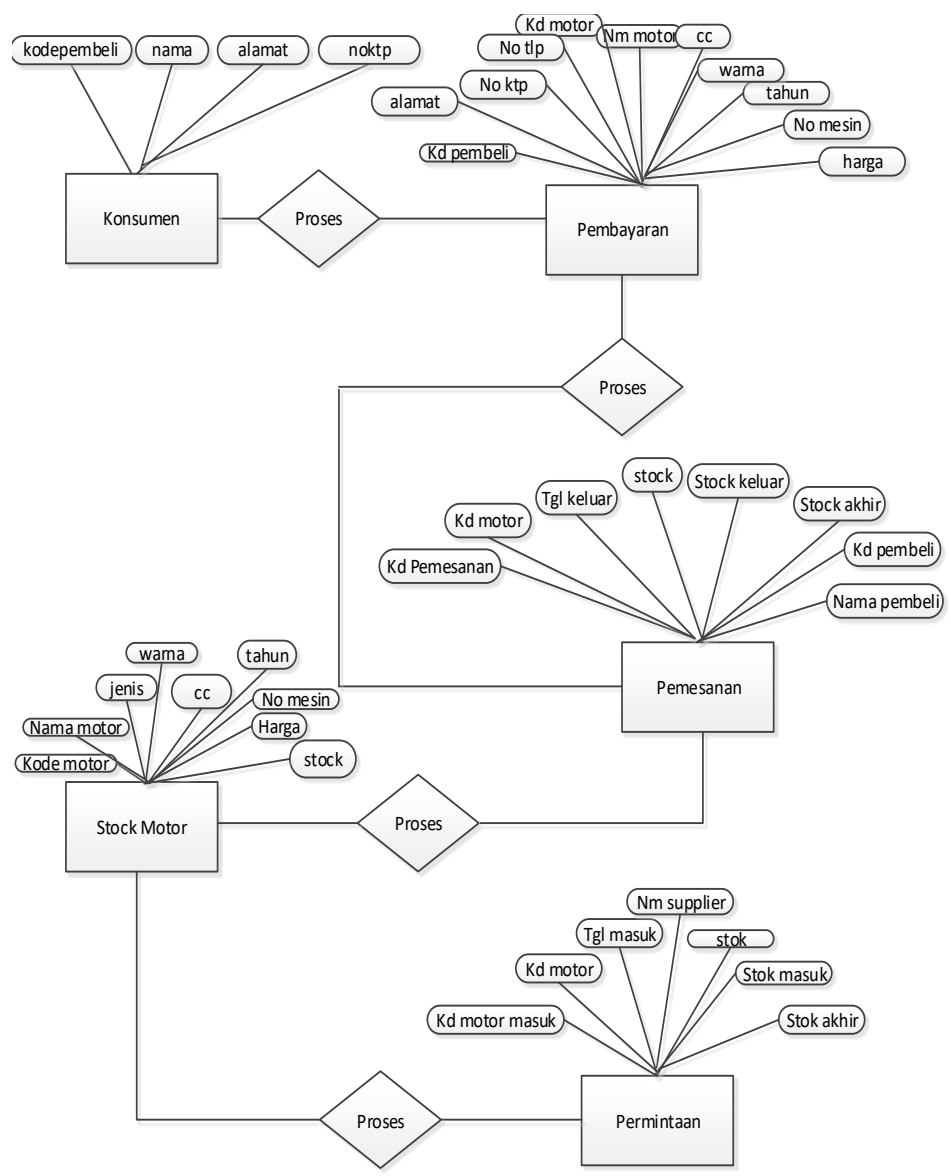

Gambar 2. Diagram ERD (Entity Relationship Diagram)

Proses selanjutnya peneliti membuat aplikasi ini dengan menggunakan java netbeans edisi 8.2 berbasis desktop dan menggunakan basisdata MySQL.

Dibawah ini adalah tampilan dari aplikasi penjualan pada Yamaha Victory Depok.

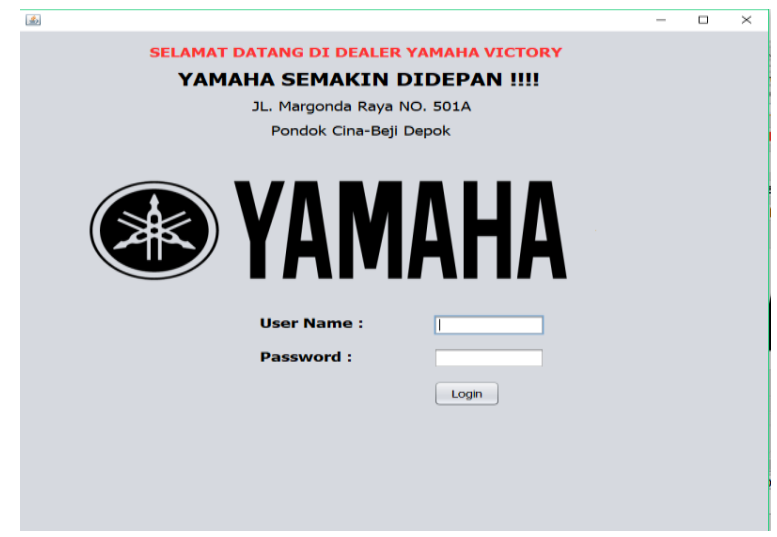

Gambar 3. Tampilan layar login

Tampilan ini terdapat pada awal program. Menu login digunakan sebagai kata kunci sebelum pengguna menggunakan program. Akses pada sistem ini diberikan kepada karyawan. Tidak sembarangan orang dapat masuk ke sistem ini. Hal ini dimaksudkan agar sistem dan data tetap terjaga dengan baik. 


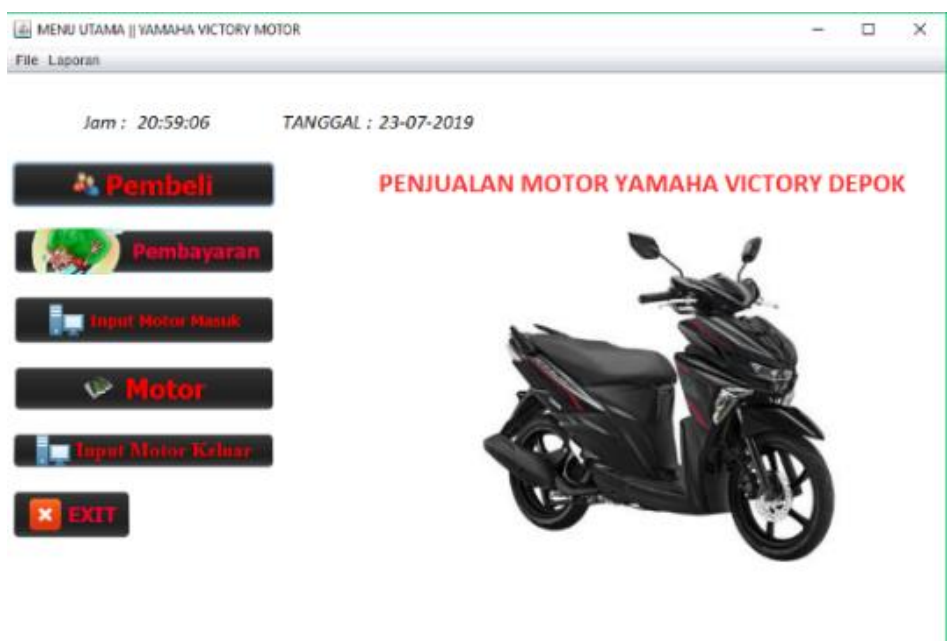

Gambar 4. Tampilan Layar Menu Utama

Layar di atas tampilan menu utama perancangan Penjualan Motor Secara Tunai Yamaha Victory. Pada layar menu utama tersedia menubar yang terdiri dari menu input data yang digunakan untuk menginput data-data pembeli, menu pembayaran yang digunakan pada saat melakukan pembayaran atau membuat bukti pembayaran kepada pembeli, laporan untuk membuat laporan data pembeli dan laporan pembayaran dan menu file terdiri menu log out dan exit yang digunakan keluar dari aplikasi tersebut.

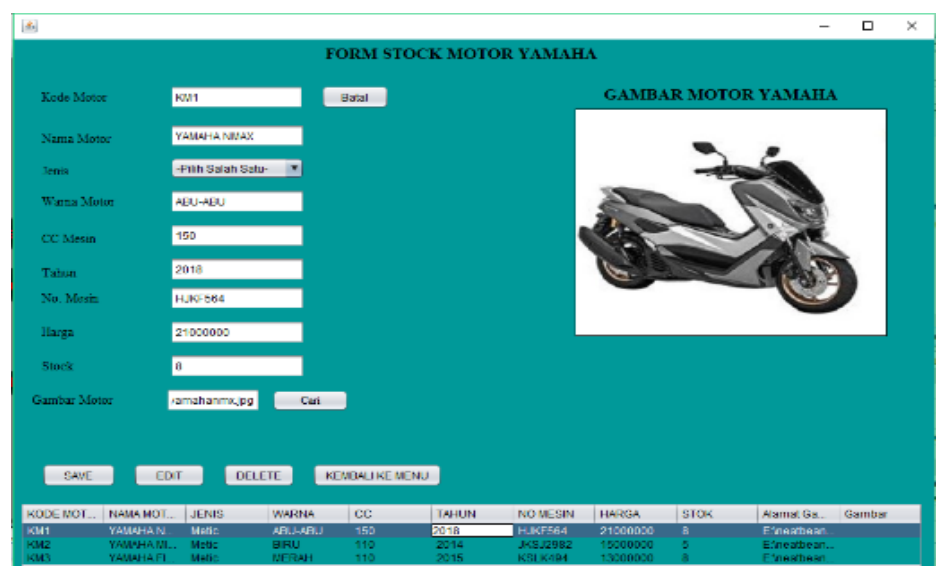

Gambar 5. Tampilan Layar Data Stok

Tampilan input data stock motor berisikan kode motor, nama motor, jenis, warna, cc, tahun, no. mesin, harga, stok. terdapat tombol save untuk menambahkan, edit untuk mengubah, dalete untuk menghapus dan kembali kemenu untuk kembali kemenu utama.

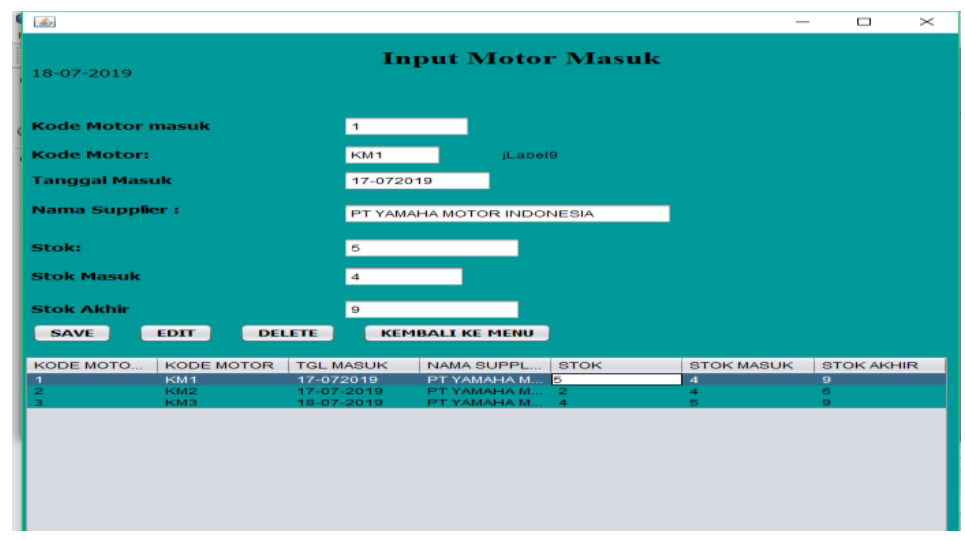

Gambar 6. Tampilan Layar Data Motor Masuk 
Tampilan input data motor masuk berisikan kode motor masuk, kode motor, tanggal masuk, nama supplier, stok, stok masuk, stok akhir. terdapat tombol save untuk menambahkan, edit untuk mengubah, dalete untuk menghapus dan kembali kemenu untuk kembali kemenu utama.

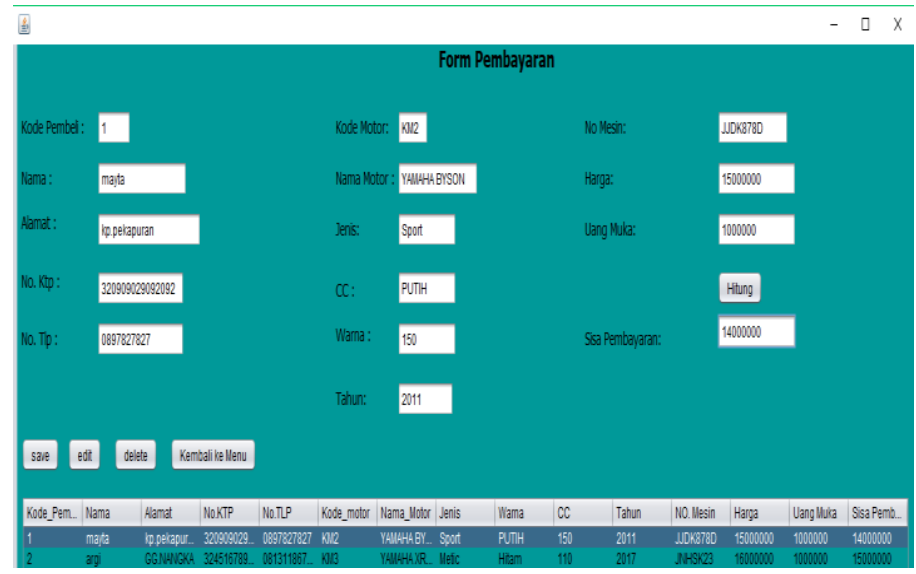

Gambar 8. Tampilan Layar Data Pembayaran

Tampilan ini adalah tampilan untuk input data pembayaran, dimana pendataan dan penginputan pembayaran di input melalui menu ini.

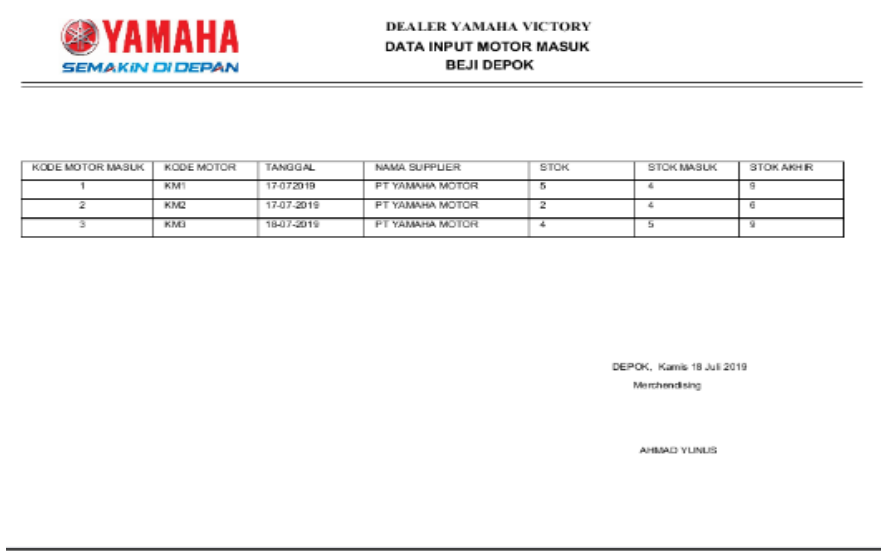

Gambar 9. Tampilan Layar Laporan Motor Masuk

Layar ini berfungsi untuk mengetahui motor masuk berisikan kode motor masuk, kode motor, tanggal masuk, nama supplier, stok, stok masuk, stok akhir. Diinput admin untuk mengetahui data motor yang sudah masuk.

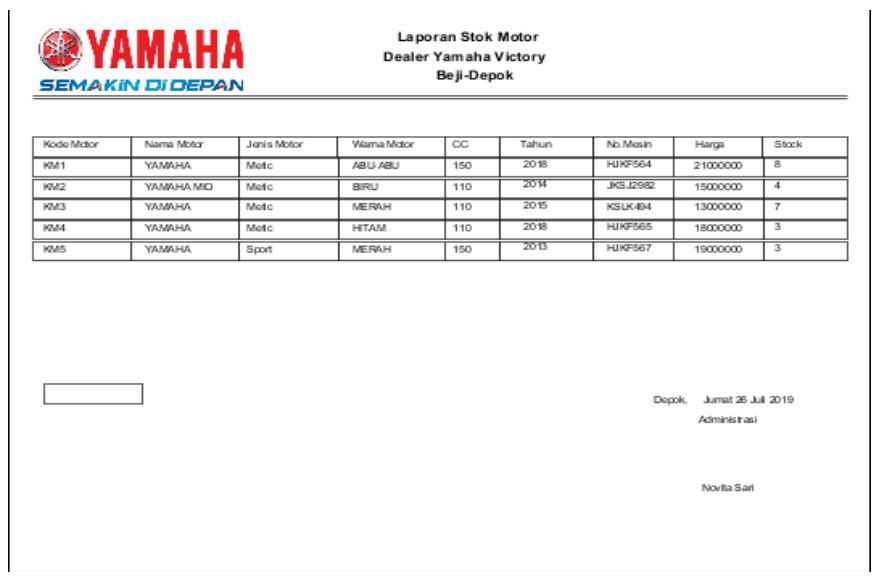

Gambar 11. Tampilan Layar Laporan Data Stock 
Layar ini berfungsi untuk mengetahui data pembayaran berisikan kode motor, nama motor, jenis motor, warna motor, cc, tahun, no. mesin, harga, dan stok motor. Diinput admin untuk melalukan pelunasan pembayaran.

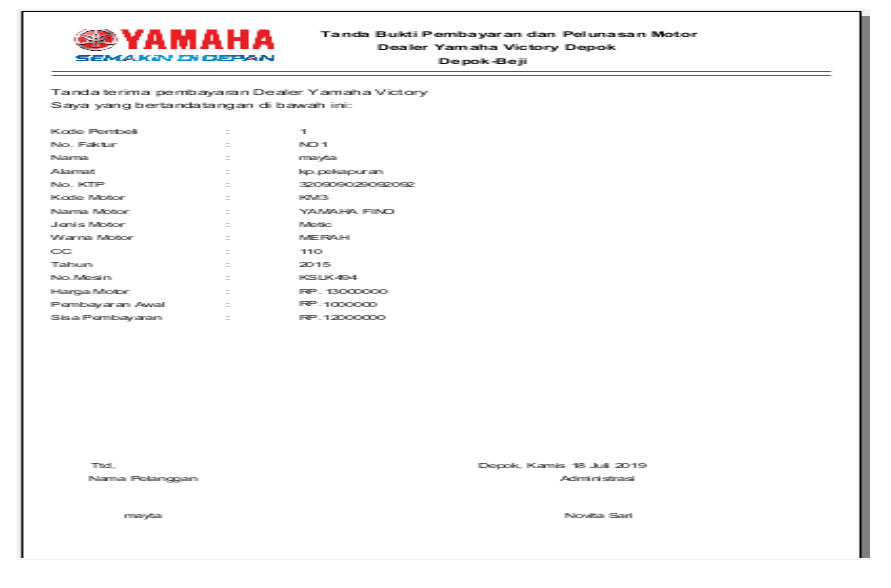

Gambar 10. Tampilan Layar Bukti Pembayaran

Layar ini berfungsi untuk mengetahui data pembayaran berisikan kode pembeli, nama, alamat, no. ktp, no. telepon, kode motor, nama motor, jenis, cc, warna, tahun, no. mesin, harga, uang muka, dan sisa pembayaran. Diinput admin untuk melalukan pelunasan pembayaran.

\section{SIMPULAN}

Dengan dibuatnya sebuah penjualan motor yang terkomputerisasi, semua yang berhubungan dengan penjualan yang terdiri dari pengolahan data dalam bentuk laporan dilakukan akan menjadi lebih sistematis. Keakuratan dan ketetepan hasil perancangan ini juga menentukan partisipasi aktif dari semua sistem, dengan adanya jasa komputer sebagai alat bantu peneliti mempunyai kesempatan untuk menjelaskan sistem ini, yaitu dengan menggunakan aplikasi khusus pada bagian penjualan akan mengalami peningkatan dalam proses pengolahan data penjualan khususnya, dibandingkan dengan sistem manual yang masih kurang akurat, proses pembuatan laporan dapat dilakukan dengan cepat dan akurat.

\section{DAFTAR PUSTAKA}

Ananta, D. (2013). Perancangan Aplikasi Penjualan Barang Berbasis Desktop Pada Cv. Metro Rantauprapat. Defri Ananta J.Informatika AMIK-LB.

Hidayat, R., Marlina, S., \& Utami, L. D. (2017). Perancangan Sistem Informasi Penjualan Barang Handmade Berbasis Website Dengan Metode Waterfall. Simnasiptek 2017.

Krismaji. (2015). Pengertian sistem menurut krismaji. In Sistem Informasi Akuntansi.

MADCOMS. (2016). PEMROGRAMAN PHP dan MySQL untuk pemula. In ANDI.

Nugroho, B. (2014). Dasar Pemrograman Web PHP-MySQL dengan Dreamweaver. Gava Media. https://doi.org/10.1016/0378-1119(87)90155-7

Wahana, K. (2015). Membangun Sistem Informasi Java dengan NetBeans dan MySQL. Andi Ofset.

Yakub. (2014). Pengantar Sistem Informasi. Igarss 2014. https://doi.org/10.1007/s13398-014-0173-7.2 